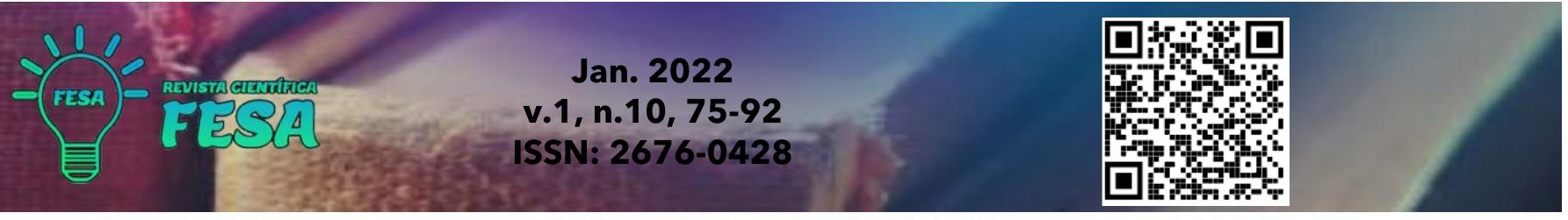

\title{
DIFICULDADES DE APRENDIZAGEM EM LINGUAGEM E INCLU- SÃO: DISCURSOS DOCENTES
}

\author{
Ruth Nely Alves de Sá ${ }^{1}$
}

\section{RESUMO}

O processo de inclusão deveria ocorrer de modo planejado, potencializando as habilidades mais desenvolvidas e estimulando o aprimoramento de outras que precisem de atenção. Contrariando essa meta, nos contextos escolares, torna-se comum a percepção de demonstrações de preconceito, velados ou não, junto a alunos que demandem algum tipo de atendimento específico por conta de suas particularidades no campo da aprendizagem. Assim, o presente artigo tem a meta de descrever a realidade da inclusão dos estudantes com necessidades educativas especiais a partir de entrevistas realizadas com docentes da Escola Municipal Elzinha Lizardo Nunes em Alto Taquari no estado do Mato Grosso. O problema fomentador deste estudo partiu da percepção de que há poucas iniciativas de dar voz aos professores de alunos com necessidades educativas especiais ao longo da Educação Básica. Dessa forma, elaborou-se uma entrevista com três perguntas abertas analisadas a partir da observação direta dos conteúdos coletados. A aplicação se deu em duas etapas, sendo a primeira com a conscientização dos docentes envolvidos e a segunda coma coleta das informações juntos a esses profissionais. Observou-se, com a análise dos dados que ainda há muito a se fazer no processo de inclusão no que tange ao trabalho desenvolvido pela escola, assim como a atuação da família nesse processo de apoio e acompanhamento. Espera-se, com este trabalho, uma maior oitiva dos principais atores do processo inclusivo de estudantes com necessidades educativas especiais: os professores.

Palavras-chave: Inclusão; Necessidades Educativas Especiais; Educação Básica; Docentes.

\section{RESUMEN}

El proceso de inclusión debe ocurrir de manera planificada, potenciando las habilidades más desarrolladas y estimulando la mejora de otras que necesitan atención. Contrariamente a este objetivo, en contextos escolares, es común percibir demostraciones de prejuicios, velados o no, con alumnos que demandan algún tipo de cuidado específico por sus particularidades en el ámbito del aprendizaje. Por lo tanto, este artículo tiene como objetivo describir la realidad de la inclusión de estudiantes con necesidades educativas especiales a partir de entrevistas realizadas a maestros de la Escuela Municipal Elzinha Lizardo Nunes en Alto Taquari en el estado de Mato Grosso. El problema que impulsa este estudio se basó en la percepción de que existen pocas iniciativas para dar voz a los profesores de alumnos con necesidades educativas especiales a lo largo de la Educación Básica. Así, se elaboró una entrevista con tres preguntas abiertas analizadas a partir de la observación directa de los contenidos recogidos. La aplicación se llevó a cabo en dos etapas, la primera con la sensibilización de los profesores implicados y la segunda recopilación de información junto con estos profesionales. Se observó, con el análisis de los datos, que aún queda mucho por hacer en el proceso de inclusión respecto al trabajo desarrollado por la escuela, así como el desempeño de la familia en este proceso de apoyo y seguimiento. Con este trabajo se espera un mayor público de los principales actores del proceso inclusivo de los alumnos con necesidades educativas especiales: los docentes.

Palabras clave: Inclusión; Necesidades Educativas Especiales; Educación básica; Profesorado.

${ }^{1}$ Mestre em Ciências da Educação pela Universidad de Dessarollo Sustentable E-mail: ruthinhans@hotmail.com 
ABSTRACT

The inclusion process should occur in a planned way, enhancing the most developed skills and stimulating the improvement of others that need attention. Contrary to this goal, in school contexts, it is common to perceive demonstrations of prejudice, veiled or not, with students who demand some kind of specific care because of their particularities in the field of learning. Thus, this article aims to describe the reality of the inclusion of students with special educational needs from interviews conducted with teachers of the Elzinha Lizardo Nunes Municipal School in Alto Taquari in the state of Mato Grosso. The problem that fosters this study was based on the perception that there are few initiatives to give voice to teachers of students with special educational needs throughout Basic Education. Thus, an interview was elaborated with three open questions analyzed from the direct observation of the collected contents. The application took place in two stages, the first with the awareness of the teachers involved and the second coma collection of information together with these professionals. It was observed, with the analysis of the data that there is still much to be done in the inclusion process regarding the work developed by the school, as well as the family's performance in this process of support and follow-up. With this work, a greater audience of the main actors of the inclusive process of students with special educational needs is expected: teachers.

Keywords: Inclusion; Special Educational Needs; Basic Education; Teachers.

\section{INTRODUÇÃO}

É notória a polêmica que existe quando se trata de educação escolar voltada a pessoas com algum tipo de necessidade especial, já que o processo de inclusão desse tipo de público ainda é algo bastante complexo. Tal fato ocorre haja vista a dificuldade de propiciar condições estruturais adequadas, como também recurso humano preparado para lidar com alunos que necessitam de um cuidado diferenciado.

Pessoti (1981) relata, acerca da história do conceito de deficiência, as diferentes formas de compreensão e tratamento de indivíduos tidos como alunos que apresentam de necessidades especiais. Nesse sentido, para esse autor, já existia na antiguidade clássica a visão sobrenatural em torno da deficiência, pois os pais abandonavam seus filhos anormais, acreditando que, desde a concepção, as crianças eram preparadas para lutar em uma guerra e, aqueles que tivessem algum tipo de anormalidade teriam seus rendimentos prejudicados, não servindo para estar numa situação de combate.

Além disso, conforme Pessoti (1981), outros conceitos mal compreendidos de deficiência contribuíram para excluir pessoas com necessidades especiais. Havia aqueles que consideravam os deficientes como seres castigados por Deus, endemoniados, citando a Reforma Luterana, que os percebia como desagregados. Os deficientes passaram a 
ser torturados, exorcizados e flagelados, muitas vezes até a morte, numa busca incessante de cura da demência a partir da expulsão de espíritos malignos dos corpos dos deficientes (PESSOTI, 1981, p. 54-68).

Ainda, segundo o mesmo autor, por meio da propagação do cristianismo na Europa, mudanças no conceito de deficiência aconteceram. Pela crença religiosa, as pessoas começaram a adotar a consciência de que deveriam ajudar os alunos que apresentam necessidades especiais, já que esses tinham alma e mereciam socorro.

Com o avanço de pesquisas e estudos em torno das deficiências físicas e suas limitações, Januazzi (1992) ressalta que, após 1960, foi sendo possível criar escolas especiais e oficinas pedagógicas, pois ficou evidente que esses indivíduos, apesar de suas características particulares, eram educáveis. Apesar disso, esses locais acabavam por confirmar a exclusão dos deficientes, já que eram tratados.

Sabe-se que o desenvolvimento de pessoas com deficiência não acontece de forma homogênea, sendo que a velocidade de assimilação de conhecimentos não é a mesma de uma pessoa considerada normal em mesma idade cronológica. De fato, Brizolara (1988 apud AMARAL, 1994), em seus estudos sobre o crescimento orgânico e emocional da criança, mostra que, desde o nascimento, esta apresenta potencial para se desenvolver, no entanto, as com deficiência tem suas chances reduzidas.

É preciso que haja uma melhor observação desta temática, uma vez que alunos com dificuldade de aprendizagem são apoiados apenas pela inclusão garantida pelas Leis voltadas aos deficientes físicos Lei №. 7.853, de 24 de outubro de 1989. Os estudos científicos a respeito deste assunto e os resultados por eles alcançados poderão garantir que, em um futuro próximo, tenhamos mais leis para os alunos com transtornos de aprendizagem e com necessidades educacionais especiais.

Dessa forma, este estudo tem o objetivo de descrever a realidade da inclusão dos estudantes com necessidades educativas especiais a partir de entrevistas realizadas com docentes da Escola Municipal Elzinha Lizardo Nunes em Alto Taquari no estado do Mato Grosso. 


\section{CONCEITO DE DIFICULDADE E DISTÚRBIO DE APRENDIZAGEM}

Dificuldade de aprendizagem, por vezes referida como desordem de aprendizagem ou transtorno de aprendizagem, é um tipo de desordem pela qual um indivíduo apresenta dificuldades em aprender efetivamente. A desordem afeta a capacidade do cérebro em receber e processar informação e pode tornar problemático para um indivíduo o aprendizado tão rápido quanto o de outro, que não é afetado por ela. No Brasil, foi Lefèvre (1975) que apresentou o conceito de distúrbio de aprendizagem como:

[...] síndrome que se refere à criança de inteligência próxima à média, média ou superior à média, com problemas de aprendizagem e/ou certos distúrbios do comportamento de grau leve a severo, associados a discretos desvios de funcionamento do Sistema Nervoso Central (SNC), que podem ser caracterizados por várias combinações de déficit na percepção, conceituação, linguagem, memória, atenção e na função motora (LEFÈVRE, 1975).

Depois disso, muito se tem discutido e abordado sobre o assunto, devido a sua importância para a aprendizagem. Para Fonseca (1995) distúrbio de aprendizagem está relacionado a um grupo de dificuldades específicas e pontuais, caracterizadas pela presença de uma disfunção neurológica, enquanto a dificuldade de aprendizagem é um termo mais abrangente relacionado ao sujeito que aprende.

Por outro lado, Ciasca e Rossini (2000) acreditam que a dificuldade de aprendizagem é um déficit específico da atividade acadêmica, ao passo que distúrbio de aprendizagem é uma disfunção intrínseca da criança relacionada aos fatores neurológicos. Os fatores neurológicos referem-se às dificuldades relacionadas à aquisição e uso da audição, fala, leitura, escrita, raciocínio ou habilidades que se referem às disfunções no sistema nervoso central. Vale ressaltar que as dificuldades de aprendizagem podem ocorrer ao mesmo tempo que outras situações desfavoráveis, como: alteração sensorial, retardo mental, distúrbio emocional, ou social, ou mesmo influências ambientais de qualquer natureza.

Desse modo, é necessário refletir sobre a colaboração na aprendizagem dessas crianças. Acredita-se não ser o mais adequado inserir todas as crianças 
com distúrbio de aprendizagem em um mesmo grupo. Para melhor distinção entre os distúrbios de aprendizagem, o ideal é tomar como base as manifestações mais evidentes que produzem impacto no desempenho da criança. Há pelo menos dois grupos que se distinguem pelo quadro que apresentam.

Enquanto em um grupo encontram-se crianças com um quadro de deficiência mental, sensorial (visual, auditiva) ou motora, que resultem de retardo mental, afecções neurológicas ou sensoriais, de outra forma, em outro grupo de crianças pode-se verificar manifestações de problemas escolares decorrentes de alterações de linguagem cuja inteligência, audição, visão e capacidade motora estão adequadas, sendo, então, o quadro de distúrbio de aprendizagem decorrente de disfunções neuropsicológicas que acometem o processamento da informação, resultando em problemas de percepção, processamento, organização e execução da linguagem oral e escrita.

Nesse sentido, um dos aspectos fundamentais numa situação de dificuldades de aprendizagem em linguagem é identificar as manifestações desses distúrbios. Inicialmente, é notório que alguns casos são perfeitamente perceptíveis, porém é fundamental e necessário que se saiba como podem aparecer as manifestações de distúrbio de aprendizagem. Há autores que relatam sobre esse assunto de uma forma que fica evidente como os sintomas aparecem ou são manifestados.

Um dos autores que trata esse assunto de uma forma bastante clara é Lerner (1989) que descreveu as manifestações como distúrbios da atenção e concentração, ao retratar os comportamentos das crianças com e sem hiperatividade e impulsividade; problemas receptivos e de processamento da informação, diz respeito à competência linguística, como as atividades de escrita, distinção de sons e de estímulos visuais, aquisição de léxico, compreensão e expressão verbal; dificuldades de leitura, manifestada pela aquisição das competências básicas relacionadas à fase de decodificação, como sendo a compreensão e a interpretação de textos, as dificuldades de escrita e presença de erros ortográficos em geral.

Acrescenta-se as dificuldades na matemática, que se revelam na aquisição da noção de números, no lidar com quantidades e relações espaçostemporais e problemas de aquisição e utilização de estratégias para aprender, 


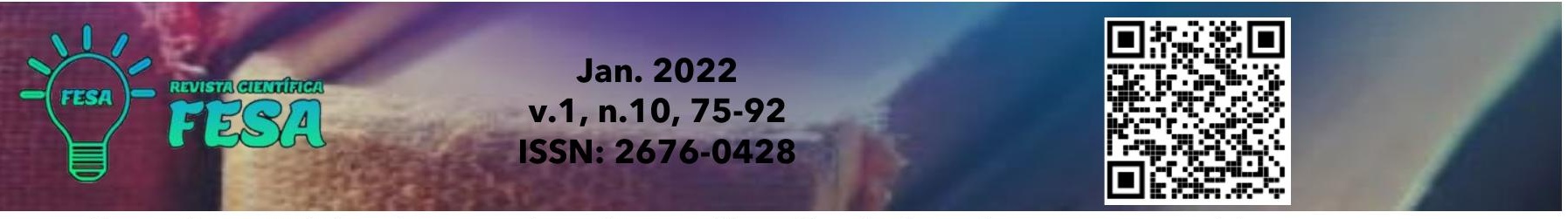

manifestados na falta de organização e utilização de funções meta cognitivas, comprometendo o sucesso na aprendizagem;

Outro ponto são definições sobre aprendizagem, a aquisição de conhecimento ou especialização que faz os indivíduos ignorarem todo processo oculto existente no ato de aprender que gera uma mudança permanente de comportamento, resultado de exposição a condições do meio ambiente. Em paralelo, tem-se um processo evolutivo e constante, que implica uma sequência de modificações observáveis e reais no comportamento do indivíduo, de forma global (físico e biológico), e do meio que o rodeia, onde esse processo se traduz pelo aparecimento de formas realmente novas compromissadas com 0 comportamento.

Tanto sob o ponto de vista neurológico como psicológico, a aprendizagem apresenta pontos comuns e significados internamente ligados que culminam para o fato de que tudo aquilo que se sabe, o homem deve aprendê-lo, porém é na escola que há um vínculo integrativo da sociedade, cuja principal forma de ação é sobre o indivíduo em seu desenvolvimento global, visando a maior possibilidade de renovação e liberdade.

Para Ciasca e Rossini (2000) o aprendiz é visualizado como um manipulador inteligente e flexível que busca a informação e procura organizá-la, integrála, armazená-la e recuperá-la, de forma ativa e ajustada às estruturas cognitivas de que dispõe internamente.

Assim, prestar atenção, compreender, aceitar, reter, transferir e agir são alguns dos componentes principais da aprendizagem. Porém, caso isso não ocorra, com o aprendiz, implica que há nessa criança um Distúrbio de Aprendizagem.

Nesse momento, é necessário definir o que é distúrbio de aprendizagem. Para isso, Lerner (1989) afirma que o Distúrbio de aprendizagem se manifesta em crianças que apresentam dificuldades de aquisição de matéria teórica, mesmo que tenham inteligência normal, e não apresentem desfavorecimento físico, emocional ou social. Conforme essa conceituação, as crianças com distúrbio de aprendizagem não são incapazes de aprender, pois não apresentam deficiência irreversível, mas sim uma forma de imaturidade que requer atenção e métodos de ensino apropriados.

Assim, de acordo com Lerner (1989) os distúrbios de aprendizagem não 
devem ser confundidos com deficiência mental. Acredita-se que uma criança tenha distúrbio de aprendizagem quando não apresenta um desempenho compatível com sua idade quando lhe são fornecidas experiências de aprendizagem apropriadas; quando apresenta discrepância entre seu desempenho e sua habilidade intelectual em uma ou mais das seguintes áreas; e ainda acerca da expressão oral e escrita, compreensão de ordens orais, habilidades de leitura e compreensão e cálculo e raciocínio matemático.

Além disso, costuma-se considerar quatro critérios adicionais no diagnóstico de distúrbios de aprendizagem. Para que a criança possa ser incluída neste grupo, ela deverá apresentar problemas de aprendizagem em uma ou mais áreas; apresentar uma discrepância significativa entre seu potencial e seu desempenho real; apresentar um desempenho irregular, isto é, a criança tem desempenho satisfatório e insatisfatório alternadamente, no mesmo tipo de tarefa; o problema de aprendizagem não é devido a deficiências visuais, auditivas, nem a carências ambientais ou culturais, nem problemas emocionais.

Sobre isso, Lefèvre (1975) conceitua distúrbio de aprendizagem como síndrome que se refere à criança de inteligência próxima à média, média ou superior à média, com problemas de aprendizagem e/ou certos distúrbios do comportamento de grau leve a severo, associados a discretos desvios de funcionamento do Sistema Nervoso Central (SNC), que podem ser caracterizados por várias combinações de déficit na percepção, conceituação, linguagem, memória, atenção e na função motora.

Em acréscimo, Fonseca (1995) traz à luz de sua teoria tanto a conceituação de distúrbio de aprendizagem, quanto dificuldade de aprendizagem. Para o primeiro, traz a ideia fundante de que o distúrbio de aprendizagem está relacionado a um grupo de dificuldades específicas e pontuais, caracterizadas pela presença de uma disfunção neurológica. Para o segundo, assevera que a dificuldade de aprendizagem é um termo mais abrangente relacionada ao sujeito que aprende, aos conteúdos pedagógicos, ao professor, aos métodos de ensino, ao ambiente físico e social da escola.

Ciasca e Rossini (2000), da mesma maneira que Fonseca (1995), fundamentam conceitos referentes aos dois distúrbios. Para o distúrbio de aprendizagem, relatam que é uma disfunção intrínseca da criança relacionada aos fatores neurológicos. Os fatores neurológicos referem-se às dificuldades relacionadas à 
aquisição e uso da audição, fala, leitura, escrita, raciocínio ou habilidades matemáticas que se referem as disfunções no sistema nervoso central. Já para a dificuldade de aprendizagem, consideram que é um termo mais abrangente e está relacionada ao sujeito que aprende, aos conteúdos pedagógicos, ao professor, aos métodos de ensino, ao ambiente físico e social da escola.

Lerner (1989) resume seus esforços teóricos ao fato de que as crianças com dificuldade de aprendizagem não são incapazes de aprender, pois não apresentam deficiência irreversível, mas sim uma forma de imaturidade que requer atenção e métodos de ensino apropriados.

Destarte, evidencia-se um resumo dos diferentes autores sobre as compreensões entre dificuldade e distúrbio de aprendizagem, de forma a contribuir para o aprofundamento do tema e, ainda, para buscar caminhos que objetivem a solução do problema da presente investigação: as manifestações de preconceito nas unidades escolares como um dos obstáculos à política de inclusão escolar de alunos com dificuldades de aprendizagem em linguagem e que apresentam necessidades educacionais especiais.

\section{DIFICULDADE E DISTÚRBIO DE APRENDIZAGEM NO DESENVOLVIMENTO ESCOLAR}

Dadas as devidas considerações sobre os conceitos de dificuldade e distúrbio de aprendizagem com base nas teorias de Lefèvre (1975), Fonseca (1995), Ciasca e Rossini (2000) e Lerner (1989), serão traçadas as formas que ambas as situações se manifestam no desenvolvimento escolar.

Para Skinner (1970), aluno aprende em mínimas partes e cumulativamente, baseando-se sempre no acerto, o que reforça e mantém o interesse em continuar. Essa técnica permitiu o surgimento do que se denomina autoinstrução, posto que o aluno pode seguir de forma independente, sendo conduzido pelo próprio programa autoinstrucional.

De acordo com o autor, as contingências estabelecidas na rotina escolar são em sua grande maioria para controle coercitivo e podem frear 0 desenvolvimento dos educandos quando estes possuem algum tipo de dificuldade. $O$ estudante se engaja em atividades principalmente para fugir de punições e quando não consegue, promove sua própria exclusão do processo 
de aprendizagem.

O uso excessivo de controle aversivo em detrimento de reforçamento positivo também se evidencia na falta de sentido que permeia a aprendizagem de conteúdos escolares. O estudante com dificuldade de aprender ou com necessidades educacionais especiais não sabe o porquê deve aprender tudo aquilo e dificilmente relata encontrar sentido para todo esforço que faz.

Trazer para o aluno, seja ele com dificuldades ou necessidades educacionais especiais, o verdadeiro motivo de se aprender algo. Para o autor, tais condições são recorrentemente insuficientes e a responsabilidade de aprender recai completamente sobre o aluno, assim como seu eventual fracasso, sem que com isso sejam levantadas reflexões acerca do que os professores poderiam fazer para facilitar e mesmo garantir a aprendizagem.

De modo análogo, para Gagné (1974) a aprendizagem é como uma mudança comportamental seguida da permanência dessa mudança. A aprendizagem é ativada por uma variedade de tipos de estimulação provenientes da interação do indivíduo com o ambiente. Essa estimulação é considerada o input para os processos de aprendizagem e gera uma modificação de comportamento, que é observada como desempenho humano, o output. A aprendizagem de habilidades intelectuais obedece a uma ordem hierárquica que se inicia com conexões estímulo-resposta, passando por cadeias, conceitos e regras, até chegar à solução de problemas.

Para o psicólogo, deve-se ter ênfase para a importância da mudança frente à aprendizagem nas performances dos estudantes, destacando-a como uma condição primordial para que um processo de ensino se realize. Para que seja efetivo é necessário que estas mudanças sejam percebidas e internalizadas pelos aprendizes sejam eles com necessidades educacionais especiais ou não. Quanto à identificação e a categorização dessas mudanças observou-se algumas categorias baseadas no referencial teórico de Gagné (1974), mais especificamente nos tipos de aprendizagem.

Primeiramente, o autor conceituou a aprendizagem a partir da prática ou do treinamento de habilidades como determinante para a evolução do estudante. Neste caso, a repetição traz a segurança necessária para o apropriamento das habilidades mínimas necessárias para se consolidar a aprendizagem.

Outra forma defendida pelo autor e aprendizagem por resolução de 
tarefas ou problemas que instiga o estudante a buscar um caminho possível para uma situação que é posta, facilitando a apreensão dos conhecimentos.

A aprendizagem por descoberta pode ser um caminho possível para sanar dificuldades de aprendizagem, pois a abertura para o novo deve ser trabalhada por todos envolvidos no processo educativo. Em paralelo, a aprendizagem contextualizada pode trazer uma ambientação que possibilitará uma situatividade do estudante no conhecimento a der aprendido.

Ainda que pareça paradoxal a aprendizagem a partir dos erros, por indução ao erro ou por tentativa e erro pode provocar a reflexão do aluno para o conteúdo em questão, já que, com esse exercício, o estudante percebe que errar faz parte do processo e que suas ações, ainda que necessitem de aprimoramento, não são o único resultado da ação. O foco é o processo.

Por último e não menos importante, Gagné (1974) conceitua a aprendizagem por associações verbais e discriminações múltiplas como um importante meio de apropriação de conhecimentos. Por meio dessa prática, o professor possibilita aos alunos a oportunidade de se expressar e fazer escolhas inteligentes para se alcançar o objetivo da ação.

Portanto, evidencia-se que existem diversas formas de se desenvolver 0 ensino com base nas teorias de Skinner (1970) e Gagné (1974), cabendo ao professor a missão de identificar qual teoria ou metodologia mais se adequa à realidade do seu alunado a fim se sanar as dificuldades de aprendizagem que se apresentem e adequar o ensino às necessidades educacionais especiais que se fizerem presentes.

\section{DIFICULDADE DE APRENDIZAGEM E O APRIMORAMENTO DE HABILIDADES ENVOLVENDO A LINGUAGEM}

Muitos estudantes irão lidar com questões relativas à linguagem e não terão nenhuma ou quase nula dificuldade. Já outras precisarão de ajuda especial para ter sucesso na mesma atividade. Isso é comum nos espaços escolares, mas os profissionais de educação devem estar atentos a casos em que uma simples dificuldade de aprendizagem na seara da linguagem pode ser, na verdade, um estudante que demande algum atendimento educativo especial.

Sobre isso, Silva (2009) postula que: 


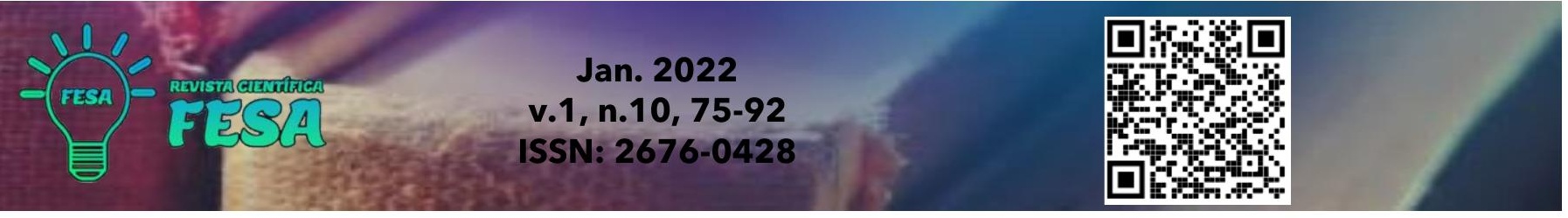

São distintas as causas que geram no educando a dificuldade de ler e escrever durante seu processo de alfabetização. As causas podem assim ser citadas: déficit perceptual, déficit linguístico, dislexia, disgrafia, disortografia, dislalia dentre outras. Muitos estudos indicam que os processos utilizados pelas crianças quando leem e escrevem não são os mesmos, pois há uma complexidade que podem determinar essas dificuldades uma vez que cada pessoa tem suas particularidades e anseios que determinam sua forma de aprender (SILVA, 2009, p. 45).

Por outro lado, há fatores sociais, culturais, econômicos, cognitivos, emocionais, institucionais ou orgânicos que também justificam as dificuldades de aprendizagem no campo da linguagem, sendo consenso que não existe uma definição comum sobre o que vem a ser uma dificuldade de aprendizagem, como e por que ela se manifesta. Sua origem pode ainda ser pulverizada e multifacetada.

O contexto das dificuldades de aprendizagem integra um grupo heterogêneo, sendo difícil identificá-las. Ainda assim, uma das manifestações mais óbvias desse obstáculo é o baixo desempenho escolar, o que não significa necessariamente que crianças tenham alguma especificidade educativa. Nesse momento, a escola deve estar preparada para lidar com isso e receber o aluno e, na mesma medida, as suas dificuldades. Silva (2009) revela ainda que:

Neste contexto, deve haver um ambiente lúdico e profissionais qualificados, para proporcionar assistência aos professores e a outros profissionais da instituição escolar, para melhoria das condições do processo educacional, bem como, a informação à família do discente sobre o processo que o mesmo está tendo na Unidade escolar (SILVA, 2009, p. 48).

Bermejo e Llera (1997) destacam que essas dificuldades que também impactam a linguagem podem ser classificadas como transitórias ou permanentes e ocorrem em qualquer momento durante o processo de ensinoaprendizagem. Esse processo corresponde a maiores comprometimentos funcionais como cognitivos, de linguagem, raciocínio lógico, cognitivos, de atenção e afetivos, podendo ser, inclusive, demandar uma necessidade educativa especial.

A partir da percepção de um não avanço na aprendizagem de conteúdos voltados à linguagem pode-se, inclusive, surgir um encaminhamento ao atendimento educacional especializado, como a sala de recursos, onde o estudante possui uma estrutura de ensino adequada para a entrega educacional, 


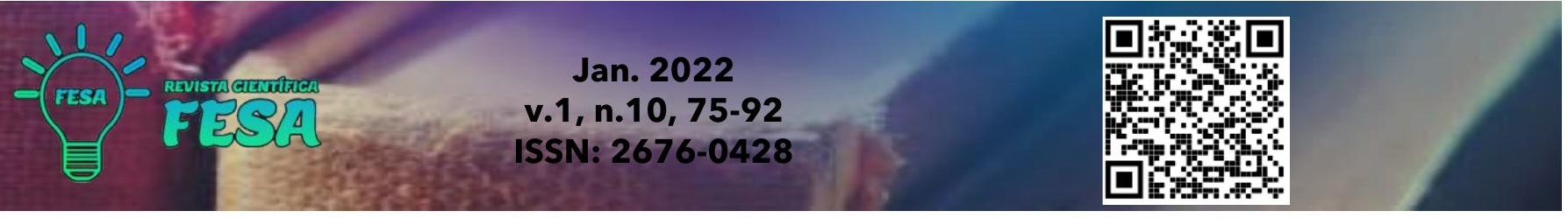

proporcionando melhores condições para a vida educacional, social e familiar.

Sobre essas dificuldades específicas, Zucoloto e Sisto (2002) listam alguns fomentadores:

As dificuldades de aprendizagem em escrita podem se manifestar por confusão, inversão, transposição e substituição de letras, erros na conversão símbolos, ordem de sílabas alteradas, lentidão na percepção visual, entre outros. Essas dificuldades podem se manifestar em áreas distintas como ao soletrar ou escrever uma palavra ditada (ZUCOLOTO; SISTO, 2002, p. 175).

Ainda no campo conceitual, torna-se imperioso revelar que as dificuldades de aprendizagem no campo da linguagem, sendo uma considerada uma necessidade educativa especial ou não, constitui-se como um fator restritivo ao ingresso no mercado de trabalho e aos contextos sociais, tendo em vista que o próprio mercado e a sociedade como um todos revelam às pessoas que as chances de se conseguir uma boa colocação profissional variam de acordo com a escolaridade e com o pleno exercício das habilidades linguísticas.

Desse modo, as dificuldades de aprendizagem específicas referem-se à forma como um indivíduo processa as informações - recebe, integra, armazena e apresenta os dados, levando em consideração sua competência e todas as realizações possíveis e esperadas. Correia (2008) completa essa percepção destacando que:

As dificuldades de aprendizagem podem, assim, manifestar-se nas áreas da fala, da leitura, da escrita, da matemática e/ou da resolução de problemas, envolvendo défices que implicam problemas de memória, perceptivos, motores, de linguagem, de pensamento e/ou metacognitivos. Estas dificuldades, que não resultam de privações sensoriais, deficiência mental, problemas motores, défice de atenção, perturbações emocionais ou sociais, embora exista a possibilidade de estes ocorrerem em concomitância com elas, podem, ainda, alterar o modo como o indivíduo interage com o meio envolvente (CORREIA, 2008, p. 47).

Inserido nesse contexto, Cruz (2009) emerge com definições objetivas que apresentam as dificuldades de aprendizagem voltadas para o campo da linguagem como uma incapacidade para aprender a ler, outras mais complexas que apontam problemas na aprendizagem das relações entre os sons e as letras, o que se traduz em dificuldades no reconhecimento de vocábulos, na aprendizagem dos seus nomes, na transformação das palavras representações 
físicas e de combinações de diferentes letras (CRUZ, 2009).

Uma dificuldade notadamente reconhecida como uma necessidade educativa especial é a dislexia que que indica um distúrbio de linguagem, embora a ideia e o consenso mais arraigados seja de que se refere a um distúrbio de leitura. Esta definição deve abarcar diferentes aspectos da dislexia dos quais três são dignos de menção, nomeadamente a sua origem neurobiológica, dificuldade de decifração, o resultado de uma deficiência na composição fonológica da língua e problemas que podem surgir na compreensão de leitura.

Dessa forma, a escola precisa deixar de lado rótulos que apenas isentam uma parcela da comunidade escolar de sua responsabilidade com o adequado atendimento aos alunos e passar a considerar que há uma expressiva quantidade de alunos que necessitam de um atendimento específico e direcionado à diminuição das dificuldades de aprendizagem, inclusive, as que surgem no aprimoramento de habilidade no campo da linguagem.

\section{ENTREVISTA COM PROFESSORES DA ESCOLA MUNICIPAL ELZINHA LIZARDO NUNES}

A partir deste ponto, serão analisadas as falas dos professores selecionados para participarem das entrevistas. Importante lembrar que foram entrevistados três professores representando de todos os docentes que atuam com alunos com necessidades educativas especiais matriculados na Escola Municipal Elzinha Lizardo Nunes.

A primeira pergunta a ser respondida de modo mais analítico pelos professores versava sobre as barreiras para inclusão de alunos, buscando mensurar as medidas tomadas para o desenvolvimento das atividades pedagógicas para o público em questão. A pergunta foi formulada da seguinte forma: Para você quais são as barreiras que impedem que a inclusão dos alunos com dificuldades de aprendizagem aconteça dentro do ambiente escolar?

O quadro a seguir traz as respostas obtidas após a aplicação da entrevista aos professores.

Quadro 1. Para você quais são as barreiras que impedem que a inclusão dos alunos com dificuldades de aprendizagem aconteça dentro do ambiente escolar? 


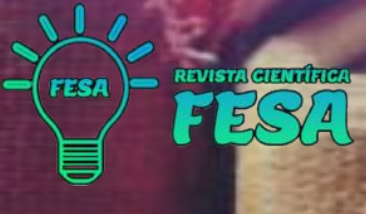

Professor I "São várias, a primeira que eu até vou citar é o despreparo dos próprios professores, há muito preconceito também, a outra falta de material e a outra falta de tempo para preparar esse material".

Professor II "Uma das principais barreiras é a falta de formação específica para lidar com esses alunos, eu não sei como lidar como agir nesta situação. Em português isso é uma barreira muito grande".

Professor III "Um dos principais dos principais fatores é a questão número, questão quantidade número e série, uma série com $5^{\circ}$ ano, $6^{\circ}$ ano, com idade entre 10(dez), 11 (onze) anos, passar acima de 25 já dificulta bastante. Por a gente ser sozinho dentro da sala de aula, esse número é muito grande não dá pra se atender individualmente e aqueles que tem dificuldade de aprendizagem eles saem prejudicados neste quesito, este é um dos requisitos e um dos principais quesitos, questão de números de alunos e a outra dificuldade é que as vezes a gente está assoberbada de trabalho e não consegue fazer uma atividade bem diversificada com eles".

Fonte: Elaborado para esta investigação.

O problema da não formação adequada dos professores para receber o aluno com necessidades educacionais especiais ou com dificuldade de aprendizagem são recorrentes em todos os relatos.

Nesse sentido, a pós-formação dos professores sugere a busca de respostas aos desafios decorrentes das novas relações entre sociedade e educação, posto que a atual realidade demanda por profissionais preparados adequadamente para atender às exigências dos avanços da ciência e da tecnologia, que redimensionam as articulações sociais entre os atores, sendo a escola a instituição responsável em preparar os profissionais que atuam nessa sociedade.

A segunda pergunta respondida de modo mais analítico pelos professores versava sobre o núcleo familiar, buscando mensurar as medidas tomadas para o desenvolvimento das atividades pedagógicas para o público em questão tendo como base um ambiente externo à escola. A pergunta foi formulada da seguinte forma: O que você pensa a respeito do núcleo familiar atual que é tão diferente do de outrora? Em que isso contribui para o não desenvolvimento do processo ensino aprendizagem?

O quadro a seguir traz as respostas obtidas após a aplicação da entrevista aos professores. 


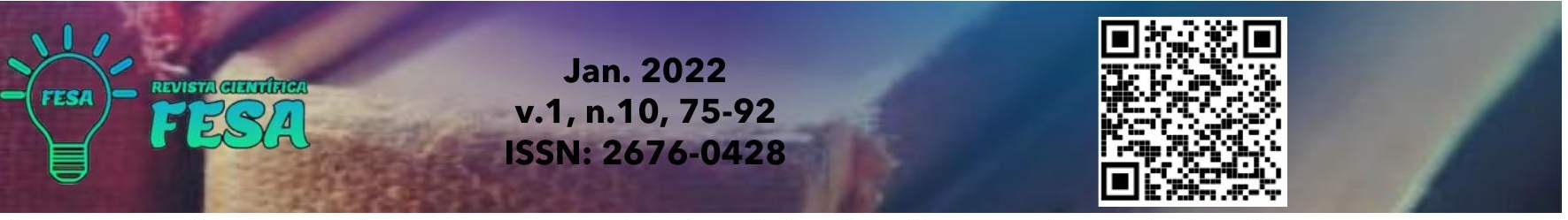

Quadro 2. O que você pensa a respeito do núcleo familiar atual que é tão diferente do de outrora? Em que isso contribui para o não desenvolvimento do processo ensino aprendizagem?

\begin{abstract}
Professor I "Atualmente as famílias não estão mais participando do ensino aprendizagem dos seus filhos, e eu acredito que isso essa é uma falha muito grande da família, porque apesar da correria toda que a gente leva nessa vida que a gente tem hoje, nós temos que ter um tempo pros nossos filhos, e o que falha muito é essa falta de compromisso dessa família com o próprio filho na escola".
\end{abstract}

Professor II "Eu acho que os pais hoje em dia estão querendo que a escola eduque os filhos deles, porque o nosso tem que é pra ensinar outras coisas está sendo pra educar os filhos deles, os pais também, os que mais tem problema na escola, não vem a escola, quando vem falam que não dão conta dos filhos então pra nós professores ser pai e mãe deles e além de tudo ensinar, então pra mim é complicado".

Professor III "O que eu penso é que a maioria as pessoas estão perdendo de ter esse núcleo familiar tão diferente do que era antes, eu creio que eles estão perdendo porque uma vez que a família está se perdendo, a família está se desmantelando e o que eu vejo muitas vezes é que a maiorias dos pais estão colocando para que nós educadores também eduquemos seus filhos está fazendo com que nós façamos também esse papel que é deles, essa problemática infelizmente acaba atingindo nossos alunos uma vez que eles não tem esse respaldo familiar, não tem essa estrutura familiar que possa ajudá-los, acompanhá-los, então fica tudo a mercê da escola e nós não temos essa capacidade de ser médicos, pais, psicólogos e educadores também".

Fonte: Elaborado para esta investigação.

A pouca proatividade da família foi o tema de todas as respostas coletadas. O Professor 2 cita que "Eu acho que os pais hoje em dia estão querendo que a escola eduque os filhos deles...". Tal cenário é preocupante, pois se evidencia uma escola despreparada para receber os alunos com necessidades educacionais especiais ou com dificuldade de aprendizagem, assim como a presença de uma estrutura familiar omissa e não integrada à rotina escolar.

A terceira pergunta a ser respondida de modo mais analítico pelos professores versava sobre percepções acerca do processo de inclusão, buscando compreender como esses profissionais encaram execução desse movimento na rotina escolar. A pergunta foi formulada da seguinte forma: O que mais te causa angústia ou frustração no processo de inclusão?

O quadro a seguir traz as respostas obtidas após a aplicação da entrevista aos professores.

Quadro 3. O que mais te causa angústia ou frustração no processo de inclusão? Professor I "O que mais está me causando angústia é saber que nós não estamos tendo reforço esse ano, que eles vão ter que passar e não vão saber todo o conteúdo 
então isso está me causando angústia se eu não conseguir que esses alunos aprendam, então no final do ano eu vou ter uma grande frustração nisso. Porque eu vou saber que tem alguns que mesmo com dificuldades vão passar e a dificuldade a cada ano vai aumentando e aí isso causa grande triste no professor".

Professor II "é não saber lidar com a situação, isso daí é uma coisa que eu não sei o que fazer, não sei com ajudar e muitas vezes e a maiorias das vezes eu não faço nada porque eu trato igualmente tento tratá-los igualmente mais a bem na verdade não é igualmente porque a partir do momento que eu não estou sendo, dando uma trabalho especializado, tendo uma tratamento individualizado pra aquele que precisa mais eu não estou tratando igual também, mais uma questão muito triste, muito angustiante realmente porque eu não sei como fazer é essa minha limitação é essa a maior problemática".

Professor III "O sistema. O sistema é muito burocrático, as vezes uma coisa muito simples poderia ser resolvido com tanta facilidade e infelizmente não há, as vezes a gente tenta, consegue, e se a gente tivesse, por exemplo se conseguisse um reforço mesmo com agente, com o mesmo professor tivesse uma hora no contra período quem sabe estes alunos estariam rendendo mais, porque se a gente já tem o contato com ele na sala de aula, nós mesmos poderíamos estar auxiliando esses alunos no contra período aí sim acredito que eles estariam melhorando".

Fonte: Elaborado para esta investigação.

As respostas dos professores da Escola Municipal Elzinha Lizardo Nunes em Alto Taquari no estado do Mato Grosso apontam para um sentimento de impotência diante do processo. Desse modo, a fim de ilustrar essa percepção, o Professor 1 cita que "...eles vão ter que passar e não vão saber todo o conteúdo então isso está me causando angústia se eu não conseguir que esses alunos aprendam, então no final do ano eu vou ter uma grande frustração nisso..." Com base nesses relatos, evidencia-se a falência a educação no que tange ao atendimento dos alunos com necessidades educacionais especiais ou com dificuldade de aprendizagem.

\section{CONSIDERAÇÕES FINAIS}

Dessa forma, foi possível trazer à tona a realidade dos professores dos alunos com necessidades educacionais especiais na Escola Municipal Elzinha Lizardo Nunes em Alto Taquari no estado do Mato Grosso a fim de fornecer um panorama da realidade desses profissionais atuantes na Educação Básica. Ainda, espera-se que os governantes direcionem esforços para o melhor atendimento formativo desses profissionais, já que a inclusão de todos é interessante para todos os membros da sociedade. 


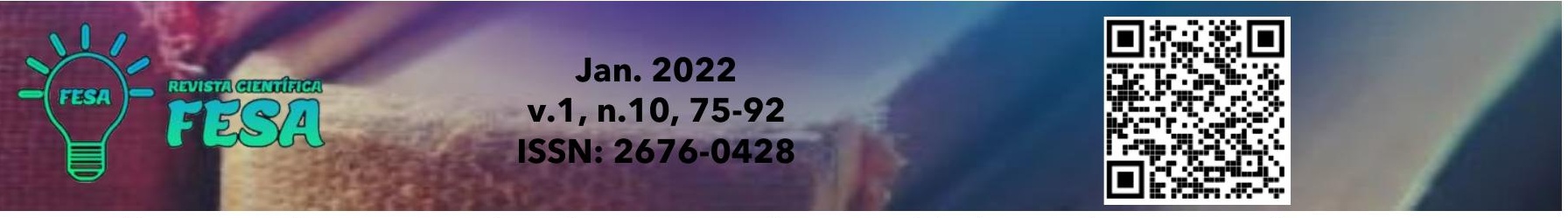

Portanto, devemos ouvir os integrantes da comunidade escolar para então propor alternativas viáveis de inclusão. O ideal é, em um primeiro momento, reconhecer o problema para então corrigi-lo.

\section{REFERÊNCIAS BIBLIOGRÁFICAS}

AMARAL, L. A. Pensar a Diferença: Deficiência. Brasília: Editora CORDE, 1994.

BERMEJO, V. S.; LLERA, J. A. B. Dificultades de aprendizaje. Madrid: Síntesis Psicológica, 1997.

CIASCA, S.M.; ROSSINI, S.D.R.: Distúrbio de aprendizagem: mudanças ou não? Correlação de uma década de atendimento. Temas sobre desenvolvimento, 8(48): 11-16, 2000

CORREIA, L. M. Dificuldades de aprendizagem específicas: Contributos para uma definição portuguesa. Porto: Porto Editora, 2008.

CRUZ, V. Dificuldades de aprendizagem específicas. Lisboa: Lidel, 2009.

FONSECA, V. Educação Especial. 2 ed. Porto Alegre, Editora Artes Médicas, 1995.

FONSECA, V. Introdução às dificuldades de aprendizagem. 2 ed. Porto Alegre: Artes Médicas, 1995.

GAGNÉ, Robert. The Conditions of Learning. New York: Holt, Rinehart; Winston, 1985.

JANUZZI, G. A Luta pela Educação do Deficiente Mental no Brasil. 2 ed. Campinas, Editora Autores Associados, 1992.

LEFRÈVE, AB. (Coord.) Disfunção Cerebral Mínima. São Paulo: Editora Sarvier, 1975.

LERNER, J. Learning disabilities: theories, diagnosis and teaching strategies. Boston: Houghton Mifflin Comp., 1989.

PESSOTI, I. Sobre a Gênese e Evolução Histórica do Conceito de Deficiência 
